\title{
Pedro Henríquez Ureña y la Utopía de América: exilios, humanismo y educación
}

\author{
(Pedro Henríquez Ureña and the Utopia of America: \\ exile, humanism and education)
}

\author{
Myriam SOUTHWELL \\ CONICET \\ Universidad Nacional de La Plata, Argentina
}

RESUMEN: El intelectual dominicano Pedro Henríquez Ureña (1884-1946) vivió una diáspora producto de las agresivas políticas norteamericanas y la conflictividad política en América Latina. En su tránsito por diferentes países aportó su perspectiva de problemática latinoamericana y los debates sobre la identidad autónoma y la conflictividad ante la necesidad de expandir las prácticas democráticas en la formación. Sus ideas tuvieron especial influencia en la educación universitaria y secundaria a través de una obra lingüística caracterizada por el hispanoamericanismo y una labor de creación de una visión de la historia lingüística de América incluyendo variedades americanas, que reconocía sus raíces peninsulares. El artículo busca recuperar su vitalidad intelectual y su entusiasmo humanista que cultivó en diversas universidades de la región.

PALABRAS CLAVES: Pedro Henríquez Ureña; Hispanoamericanismo; humanismo; estética.

ABSTRACT: The Dominican intellectual Pedro Henríquez Ureña (1884-1946) was forced into exile as a result of the United States' policy of aggression and political conflict in Latin America. As a member of the South American diaspora, Henríquez Ureña shared with different countries his perspective on the problems facing Latin America, debates about autonomous identity and conflict, and the need to educate people in democratic practices. His Spanish-Americanist ideas on language and his recognition of the Spanish roots of Latin America's linguistic past had a particularly strong influence on university and secondary education. This article is an attempt to recapture the intellectual vitality and humanistic enthusiasm he inspired in universities across the continent.

KEYWORDS: Pedro Henríquez Ureña; Spanish-Americanism; humanism; aesthetics. 
Aquel humanista excelso, quizás único en el continente, hubo de viajar durante años y años entre Buenos Aires y La Plata con su portafolio cargado de deberes de chicos insignificantes, deberes que venían corregidos con minuciosa paciencia y con invariable honestidad en largas horas nocturnas que aquel maestro quitaba a los trabajos de creación humanística. ‘¿Por qué pierde tiempo en eso?', le dije alguna vez, apenado al ver cómo pasaban sus años en tareas inferiores. Me miró con suave sonrisa y su reconvención llegó con pausada y levísima ironía: 'Porque entre ellos puede haber un futuro escritor'.1

Las primeras décadas del siglo XX latinoamericano fueron un momento de revisión del canon liberal que había hegemonizado la vida social en el siglo XIX. Se trató de años de tránsito, de ideas nómades, todo estaba "por ser" o despidiéndose de lo que era. Probablemente no se había puesto de manifiesto de forma tan evidente la "juventud de América Latina" hasta que la "vieja" Europa sintió el síntoma del agotamiento que sobrevino con la Gran Guerra. Sigmund Freud, decepcionado, planteaba que la guerra le había arrebatado al mundo todas sus bellezas. ${ }^{2}$ La década de 1920 fue poderosa en la configuración de movimientos de vanguardia estéticas y políticas que pusieron de relieve las discusiones sobre la libertad y el cambio social. ${ }^{3}$

Pedro Henríquez Ureña vivió casi toda su vida fuera de su país natal, en sucesivos exilios. Fue como tantos intelectuales caribeños, ciudadanos de un Estado débil, simultáneamente colonial y poscolonial. ${ }^{4}$ Dominicano de origen, en 1901 viajó en Nueva York y en distintas ocasiones en Cuba (la primera en 1904); estuvo en México desde 1906 en los años decisivos del gobierno de Porfirio Díaz, volvió a comienzo de la Revolución y también en la década del '20. Realizó estudios de doctorado y fue profesor en Minnesota en 1920 y finalmente vivió dos décadas en la Argentina (entre 1925 y 1946). Tuvo siempre presente la larga tradición del exilio, que marcó sus lecturas, sus posiciones políticas y sus proyectos. Esa tradición estuvo presente en dos de los intelectuales que más admiró: José Martí (1853-1895) y Eugenio M. de Hostos (1839-1903). Fue así, uno de los precursores de la diáspora caribeña; el Caribe, un espacio marcado -y fragmentado- por la esclavitud africana, por constantes inmigraciones y emigraciones. ¿Cómo construir el archivo de una memoria tan plural y accidentada?. ${ }^{5}$

\footnotetext{
${ }^{1}$ Rafael Arrieta citado por Leila Guerriero, Pedro Henríquez Ureña (1884-1946) El extranjero (Agencia literaria virtual Librusa, 2003) 4.

${ }^{2}$ Patricia Funes, Salvar la Nación. Intelectuales, cultura y política en los años veinte latinoamericanos (Buenos Aires; Prometeo, 2006), 13-21.

${ }^{3}$ Beatriz Sarlo, Una modernidad periférica: Buenos Aires 1920 y 1930 (Buenos Aires: Nueva Visión, 2007), 23.

${ }^{4}$ Arcadio Díaz Quiñones, "Pedro Henríquez Ureña: Modernidad, diáspora y construcción de identidades", en) Modernización e identidades sociales, comp. Gilberto Giménez y Ricardo Pozas H. (México, Universidad Nacional Autónoma de México, 1994), 59-117.

${ }^{5}$ Arcadio Díaz Quiñones, "Pedro Henríquez Ureña (1884-1946): la tradición y el exilio", en Sobre los principios: Ios intelectuales caribeños y la tradición (Buenos Aires: Universidad Nacional de Quilmes Editorial, 2006), 167-253.
} 
Su padre era médico y colaboró activamente con Eugenio María de Hostos en la Escuela Normal en 1880. Actuó en la vida política, fue Ministro de Relaciones Exteriores en 1901 y llegó a ser Presidente de la República en 1916, aunque fue un presidente errante ya que ese mismo año se inició la ocupación militar de los Estados Unidos de América, que se extendió hasta 1924. El clima de represión vivido por Henriquez Ureña redundó en su mirada pacifista, integradora y de pluralidad cultural. Su madre, Salomé Ureña, fue una mujer dedicada a las letras y al desarrollo de instituciones educativas, en un medio desbastado por interminables guerras. Fundó el Instituto de Señoritas (entre 1881 y 1893) que funcionaba en su propia casa. Fue por ello recordada como la fundadora de la educación superior para mujeres en Santo Domingo.

Vale la pena pensar en el nuevo escenario que se configura para la educación a partir de la revisión estética de ese período que se abre luego de la finalización de la Primera Guerra Mundial, período de revisión y renovación vinculadas fundamentalmente a las siguientes cuestiones o problemas: la idea de crisis, de modernidad, el rol de los intelectuales y la política, la nación, el antimperialismo, los proyectos políticos de transformación social, la interpelación/representación de las clases subalternas, en términos de clase, étnicos y/o etarios (obreros, campesinos, jóvenes), la idea de cultura como portadora de valores emancipatorios ${ }^{6}$, una idea muy prolífica para la experimentación pedagógica.

\section{El clima cultural de la época}

El clima social de la post-guerra ponía en crisis los preceptos más racionalistas que había instalado el liberalismo decimonónico y propiciaba la inclusión de formas de conocimiento ligadas a la espiritual y sensibilidad, más allá de la preeminencia de la razón. La crisis del momento fue predominantemente interpretada como una crisis espiritual. Ello configuró un marco importante para el surgimiento del espiritualismo, una vinculación mayor del conocimiento con sus razones social y contextual, que incluyó desde la revisión de la pedagogía tradicional hasta las experiencias conservadoras y eclesiales de los años ‘ 30 .

Posteriormente, durante la década del ' 30 , el discurso político latinoamericano hará pie en una concepción de las sociedades que tendió a desestructurar la noción liberal de la libre asociación de individuos. A diferencia de aquella imagen, el corporativismo planteó un escenario de la sociedad integrada por grandes cuerpos colectivos, en los que los derechos individuales estaban subordinados al destino del colectivo pueblo, o a los intereses de la corporación de pertenencia. Por otra parte, esta etapa se encuentra marcada por una mayor intervención del estado en las relaciones sociales, como estructurador, organizador, mediador de dichas relaciones.

Nos interesa explorar a través de la figura de Pedro Henríquez Ureña, las complejas relaciones entre internacionalismo, humanismo y docencia con perspectiva latinoamericana en un período en el que se despliegan formas contrahegemónicas de poder, respecto de sus precedentes (como el Estado oligárquico) y analizar la generación de formas de

\footnotetext{
${ }^{6}$ Funes, Salvar la Nación, 19.
} 
pensar críticas y alternativas al orden instituido, los cánones y las genealogías desplegadas con anterioridad. La crisis desarrollada a partir de la Gran Guerra, la relativización de Europa como faro de la cultura y la creciente oposición a las agresivas políticas militares de Estados Unidos sobre la región fueron generando dudas, rumbos significativos y un novel continente de sentidos en el mundo de las representaciones. Como destaca Funes la revolución, el socialismo, el panamericanismo, el antiimperialismo, el indianismo, el progreso y -en menor medida- la democracia fueron tópicos que recorrieron la reflexión de los actores que se ubicaron desde el campo de la cultura y la teorización social. ${ }^{7}$ Pero, especialmente, recayó sobre ellos la tarea de pensar y crear interpretaciones y lecturas en torno a la identidad, entidad de sentido conformada desde múltiples visiones y ambivalentes significados al calor de una discusión que atravesaba tanto el plano filosófico-cultural y estético-político.

Los educadores se vieron interpelados por este clima cultural y por el florecimiento del espiritualismo que -a través de distintas expresiones- iban a interpelar la tarea pedagógica con nuevos sentidos. Asimismo, la crisis social y lo inconcluso de algunas promesas del desarrollo educativo del siglo XIX, contribuyeron a la erosión del sujeto liberal. En palabras de Patricia Funes "La Primera Guerra Mundial limó todas las mayúsculas decimonónicas: Razón, Civilización, Progreso, Ciencia". ${ }^{8}$ En ese contexto se desplegaron valores éticos y estéticos contra el positivismo: "fue menester liberarse del peso de una generación positivista, una generación que al desdeñar los valores éticos y estéticos dejó caer en el corazón argentino la gota amarga del escepticismo". ${ }^{9}$

Pedro Henríquez Ureña fue el gran artífice del concepto moderno de cultura hispanoamericana; concebía a la modernidad como un conflicto del orden frente a la anarquía, y al letrado al servicio del "bien público". ${ }^{10}$ En México, José Vasconcelos reconoció rápidamente el valor que Henríquez Ureña traía de su experiencia del Ateneo de la juventud, de sus diálogos con el movimiento reformista universitario. ${ }^{11}$ Su posición era contraria al positivismo que se encontraba ya en retroceso. Sin embargo, su posición también va a ser distinta respecto del nacionalismo que alcanza vuelo en las primeras décadas del siglo XX. Desde finales de 1931 hasta 1933 Henríquez Ureña fue Superintendente de Educación en Santo Domingo, en la primera etapa del gobierno de Rafael Leónidas Trujillo y allí planteó las confusiones que producían las diferentes denominaciones asignadas al país: la Española, Santo Domingo, Haití, República Dominicana, Hispaniola, Quisqueya y la conclusión de que la imposibilidad del nombre encierra otras imposibilidades. ${ }^{12}$ Sin embargo, su afán de establecer un canon iba más allá de a construcción nacional; en ella residía, en buena

\footnotetext{
7 Ibidem, 17.

8 Ibidem,13.

${ }^{9}$ Héctor Ripa Alberti, discurso en Asamblea Universitaria, 1921. http://biblioteca.clacso.edu.ar/clacso/ gt/20101109120908/24alberdi.pdf

${ }^{10}$ Díaz Quiñones, "Pedro Henríquez Ureña", 170.

11 Ibidem, 173

12 Ibidem, 181.
} 
medida su Utopía de América. ${ }^{13}$ La construcción de las identidades en una síntesis distinta de como prevalecía en diversas otras naciones de América, a pesar de que el temor a la relación con Haití fuera constitutiva de la construcción de nación dominicana.

La obra lingüística de Henríquez Ureña se ubica dentro de una tradición de estudios caracterizada por el hispanoamericanismo. Las ideas de Ureña sobre la identidad cultural de la América española, fueron tomando forma en un proyecto civilizatorio al que denominó la utopía de América. Se trataba de un proyecto intelectual culturalista que refería a lo hispanoamericano ubicado en la tensión entre lo universal, la cultura humanista, y lo particular dado en este caso por las tradiciones, costumbres e historia nacionales. ${ }^{14}$ Fernando Valerio-Holguín lo ha caracterizado como "un mulato intelectual europeizado" en cuya obra ha sido elidido el carácter mestizo, negro, africano, antillano de su matriz cultural de origen. ${ }^{15}$

\section{La síntesis de Rodó}

En el marco que estamos describiendo, los contenidos y significados inherentes de los discursos y representaciones pujaron por definir qué era la nación en la arena filosóficacultural; por otra parte, se hizo evidente en el plano político la intención de los intelectuales de cristalizar solidaridades colectivas y (re)crear una "comunidad imaginada" a través de ciertas inclusiones y exclusiones. Las teorización del uruguayo José Enrique Rodó, específicamente de Ariel tuvieron una gran influencia en los intelectuales de la América Latina de esos años. La noción de la juventud como impulsor del cambio social por una parte, y el desarrollo de los valores espirituales en oposición al materialismo de la cultura norteamericana por otra, propició que el texto de Rodó tanto la cultura política como el desarrollo filosófico del individualismo, aspectos a su vez vinculados a la vida democrática que Rodó proponía. $^{16}$

En el terreno pedagógico se desarrolló una temprana influencia de las corrientes espiritualistas, una suerte de idealismo humanizante de matriz bergsoniana, que a través de la obra de Rodó tuvieron una importante circulación en América Latina. A través de su obra -sobre todo el texto la Utopía de América- Henríquez presentó la historia de la cultura en la América hispánica en un objeto de estudio que logró clasificar y ordenar un complejo entramado de costumbres, expresiones estéticas y artísticas, así como de tendencias literarias y filosóficas diversas, para brindarnos un panorama de la esencia hispanoamericana, vinculada con la existencia de una forma de expresión y por tanto de representación común del mundo: el idioma español. ${ }^{17}$ Henríquez Ureña produjo una con-

\footnotetext{
${ }^{13}$ Ibidem, 176.

${ }^{14}$ Laura Moya Lopez, "Pedro Henríquez Ureña: la Identidad Cultural Hispanoamericana en "La Utopía de América" Revista de la UNAM 20 (2000): 69.

${ }^{15}$ Fernando Valerio Holguín, "Pedro Henríquez Ureña: utopía del silencio", Caribbean Studies 39 (1-2) (2011): 195-221.

${ }^{16}$ Alexandra González and Marco Antonio Solórzano, "La conformación de una genealogía intelectual. El homenaje a Gabino Barreda (1908)", Historia y Espacio 41 (2013): 17-37.

${ }^{17}$ Moya Lopez, "Pedro Henríquez Ureña", 34.
} 
figuración potente en torno a sus estudios sobre la lengua porque entendía que la lengua era una cosmovisión elaborada por una comunidad, en la que los individuos se producen, se cohesiones, se comunican.

Escribe Henríquez Ureña sobre el momento augural de las independencias latinoamericanas:

\begin{abstract}
Apenas salimos de la espesa nube colonial al sol quemante de la independencia, sacudimos el espíritu de timidez y declaramos señorío sobre el futuro. Mundo virgen, libertad recién nacida, repúblicas en fermento, consagradas a la inmortal utopía: aquí habían de crearse nuevas artes, poesía nueva. Nuestras tierras, nuestra vida libre, pedían su expresión [...]. Nuestra literatura absorbió ávidamente agua de todos los ríos nativos: la naturaleza, la vida de campo, sedentaria y nómada; la tradición indígena; los recuerdos de la época colonial; las hazañas de los libertadores; la agitación política del momento... La inundación romántica duró mucho [...]. Cuando las aguas comenzaron a bajar, no a los cuarenta días bíblicos sino a los cuarenta años, dejaron tras sí tremendos herbazales, raros arbustos, y dos corpulentos árboles, resistentes como ombúes: el Facundo y el Maritín Fierro. ${ }^{18}$
\end{abstract}

La profunda intervención de Henríquez Ureña se debe a su desarrollo del hispanoamericanismo en sus intervenciones como antólogo, traductor y organización, pero también a los diálogos que entabló con otros intelectuales. Entre otros, José Carlos Mariátegui (1894-1930) se identificaba con las pautas interpretativas de Henríquez, también podemos pensar en su influencia en el pensamiento de Ricardo Rojas, Alejandro Korn y Coriliano Alberini.

\title{
Utopia de América y la educación universitaria como su terreno
}

Henriquez Ureña se posicionó en la tensión entre lo universal -la cultura de las humanidades- y lo particular -las expresiones culturales nacionales- y pensó productivamente esa tensión a través de la formulación de una utopía, es decir, de un esfuerzo por construir una imagen de la sociedad deseable en que la armonía sería el valor dominante. ${ }^{19}$ En esa construcción, no se concentró en los aspectos políticos y socioeconómicos de la vida latinoamericana -puede qu eallí residan algunos de los reproches que se le han formulado, respecto a no ser portavoz de la explotación socioeconómica de base racial- sino que, en las coordenadas predominantes de la época, ancló en la dimensión culturalisla en tanto semillero de transformación, terreno para la perfectibilidad moral y espiritual.

Ese utopismo funcionaba señalando que eran posibles otras formas de vida, acentuando la idea de cambio y transformación, dos condiciones básicas de la idea-fuerza de progreso. Con ello, Henríquez Ureña apuntó no sólo a poner en escena una memoria histórica sobre la vida cultural de Hispanoamérica, sino que además contribuyó a perfilar una utopía, un proyecto cultural que, si bien en sí mismo era irrealizable como toda utopía,

\footnotetext{
${ }^{18}$ Pedro Henríquez Ureña, Seis ensayos en busca de nuestra expresión [1928] (Buenos Aires: Cielo Naranja, 2006), 5 .

${ }^{19}$ Moya Lopez, "Pedro Henríquez Ureña", 79.
} 
su importancia radicó en orientar la vida intelectual del autor hacia ese fin²0, otorgándole sentido y dirección a sus intervenciones públicas y actividades de docencia.

\begin{abstract}
La llamada utopía de América de Pedro Henríquez Ureña no es solamente el título de un discurso que el autor pronuncia en Argentina, sino un verdadero proyecto civilizador que lograría integrar a Hispanoamérica. Sus componentes fundamentales eran los siguientes: en primer lugar, la discusión en torno al papel de la educación pública, la Universidad y la alta cultura; en segundo lugar, el referente griego de la cultura humanista y su ideal de progreso, y finalmente su aguda reflexión sobre el sentido de las utopías en América. ${ }^{21}$
\end{abstract}

Así, reflexionar sobre la universidad significó la defensa de un proyecto que los integrantes del Ateneo de la Juventud de México (1909-1914) compartieron con Justo Sierra, quien fuera ministro de Instrucción Pública, a partir de 1905. Este proyecto consistió en advertir los logros que la educación positivista había traído consigo: el carácter laico y racional de la educación impartida en México a partir de $1867 .{ }^{22}$ Un momento clave de la posición antipositivista fue en el homenaje que se hizo en 1908 a Gabino Barreda intelectual de formación positivista, quien había impulsado y dirigido la primera Escuela Nacional Preparatoria de México y -a través de ella- la educación laica, gratuita y obligatoria. Este acto en el que un prominente grupo intelectual con una incidencia significativa en las altas esferas de la política, buscó apropiarse de una emblemática figura del positivismo nacional, para hacerle un homenaje, veintisiete años después de su fallecimiento, para inscribirlo en una pujante tendencia antipositivista, merece toda una consideración en torno a las disputas por la hegemonía que se producen en los círculos educacionales universitarios. ${ }^{23}$

En el homenaje a Gabino Barreda, el mismo Henríquez Ureña pronunció un discurso en el que defendía estas ideas, y terminaba anunciando tres grandes vetas de transformación educativa: la renovación filosófica en México, la fundación de la Universidad y el papel activo que desempeñaría la nueva generación, es decir, la suya. La fundación de la Universidad Nacional de México en 1910, y en particular la fundación de la Escuela de Altos Estudios, significó para los ateneístas en general y para Henríquez Ureña en particular la apertura de nuevos espacios para el ejercicio crítico y el estudio institucionalizado de las humanidades. En carta a Alfonso Reyes, fechada en febrero de 1908, escribe Pedro Henríquez Ureña:

\footnotetext{
${ }^{20}$ Ibidem, 80.

${ }^{21}$ Ibidem, 82.

${ }^{22}$ Moya Lopez, "Pedro Henríquez Ureña", 83.

${ }^{23}$ En sus Memorias Henríquez Ureña afirma: "Al día siguiente la prensa toda se lanzó en contra nuestra. Sólo quedó ilesa la fiesta de la noche, y uno que otro discurso de la mañana: el de Cravioto, por ejemplo. Los católicos y los positivistas (cuya preponderancia en el gobierno de México es ya antigua) se sintieron atacados, y unos y otros arremetieron a insultos". [Pedro Henríquez Ureña, Memorias, Diarios de Viaje (México: Fondo de Cultura Económica, 2000), 120-121]. Sobre el acto de homenaje a Gabino Barreda puede consultarse Alexandra Pita González y Marco Antonio Vuelvas Solórzano, "La conformación de una genealogia intelectual. El homenaje a Gabino Barreda (1908)" Historia y Espacio 41, (2013): 17-37 y Susana Quintanilla, Nosotros, la juventud del Ateneo de México (México: Tusquets, 2009).
} 
Cierto que lo que los positivistas hacen es malo; pero lo juzgamos así porque queremos progresar y no retrogradar. Mientras tanto no debe dejarse paso a la reacción. Figúrate que el Dr Vázquez Gómez es instrumento de la Compañía de Jesús, y que los jesuitas han intrigado tanto con don Porfirio que éste llegó a decirle a don Justo que veía algo digno de tomarse en consideración en la propuesta de Vázquez Gómez de que la enseñanza preparatoria se dejara en manos de particulares; así, pensaba, se dedicaría ese dinero a la primaria. En manos de particulares es decir en manos de lo curas; pues ¿qué particulares sino ellos cuentan con los medios de instalar colegios? La manifestación resulta más oportuna de lo que hubiéramos pensado. ${ }^{24}$

En los artículos "La Universidad", de 1914, que recogía partes sustanciales síntesis de su tesis de licenciatura, y "Las universidades como instituciones de derecho público" de 1915, Henriquez Ureña se explayó y fundamentó aspectos político-conceptuales -que son frecuentes hoy, pero no lo eran en esos años- en torno del peculiar vínculo entre el Estado y la cultura universitaria, vínculo de sosten y autonomización, de preservación y de libertad simultáneamente, como claves del carácter público y el desarrollo autónomo de esa institución. La tesis de Henríquez Ureña puso en el centro discusión el establecimiento de la Universidad Nacional como persona juridica, cuya independencia le permitiría desarrollar libremente muchas actividades y organizarse como entidad autónoma. ${ }^{25}$ Podríamos ubicar estas producciones, como antecedente directo del movimiento reformista universitario que estallará a partir de 1918.

La inauguración de la Universidad Nacional de México -fundada por Justo Sierra en 1910 - y de la Escuela de Altos Estudios significaron la definición de un espacio académico y político para el estudio de las humanidades. La instalación de la Universidad, su base juridica y los componentes educacionales de origen, se basaban en una filosofía humanista, una fuerte oposición a las formas del dogmatismo que sintetizaban en torno al positivismo, y una significativa vinculación entre humanismo y los valores de la identidad hispanoamericana.

Para Henríquez Ureña la Escuela de Altos Estudios era una parte central del proyecto impulsado por el Ateneo de la Juventud, porque era un centro desde el cual impulsar las ciencias, las humanidades y la alta cultura desinteresada, modificando una tendencia que él encontraba que se había ido dando en América Latina, que se había orientado a ilustrar para dirigir socialmente ${ }^{26}$ :

No arredra la necesidad de tocar la religión y a la leyenda, a la fábrica social y a los sistemas políticos. Mira hacia atrás y crea historia; mira al futuro y crea utopías, las cuales, no lo olvidemos, pedían su realización al esfuerzo humano. Es el pueblo que inventa la discusión; inventa la crítica. Funda el pensamiento libre y la investigación sistemática. ${ }^{27}$

\footnotetext{
${ }^{24}$ Alfonso Reyes and Pedro Henríquez Ureña, Correspondencia. 1907-1914 (México, Fondo de Cultura Económica, 1986) 93.

${ }^{25}$ Moya Lopez, "Pedro Henríquez Ureña", 80.

${ }^{26}$ Ibidem, 81.

${ }^{27}$ Pedro Henríquez Ureña, "La cultura de las humanidades", en La utopía de América, prólogo de Rafael Gutiérrez Girardot, compilación y cronología Ángel Rama and Rafael Gutiérrez Girardot (Caracas: Biblioteca Ayacucho, 1978), 12.
} 
Esta cita muestra el peso de las humanidades entendidas como una cultura, donde anidaba la posibilidad de la libertad intelectual peo también las bases de lo que el autor denominaría utopía: la posibilidad del progreso mediante el esfuerzo individual y con ello una contraposición con el positivismo, pero también una diferencia sustancial frente a aquellos que afirmaban un carácter cíclico de la historia. ${ }^{28}$ Su articulación era una formación en el largo plazo sobre la base de una dinámica que incluiria y producía humanismo, adquisición de conocimiento, transformación, talento individual, progreso y espíritu crítico. La fe en el progreso intelectual y cultural, en la mejora de su situación individual y colectiva, conducía a entre el aumento de conocimientos y el crecimiento de cada ser humano. ${ }^{29}$

\section{Entreguerras en Argentina: Docencia, estética y emancipación}

En el contexto del clima que estamos presentando, en 1921 se realizó en México un Congreso Internacional de Estudiantes americanos al que concurrieron cinco platenses, del Colegio Nacional dependiente de la Universidad Nacional de La Plata, Héctor Ripa Alberdi y Arnaldo Orfila Reynal. Al año siguiente llegó Pedro Henríquez Ureña a Buenos Aires, integrando la misión mexicana presidida por el Ministro de Educación José Vasconcelos, enviada para asistir a la trasmisión del mando presidencial de Hipólito Yrigoyen. En 1924 la tendencia política en México cambió y Henríquez Ureña perdió su cargo en el Instituto de Intercambio Universitario. Necesitaba salir de México y fue así que fue convocado a la Argentina, específicamente convocado para la reforma del plan de estudios del Colegio Nacional de La Plata (colegio universitario que sería equivalente con escuelas preparatorias), donde tendrá a cargo tres cátedras de Castellano y también como docente en el Instituto del Profesorado Secundario de Buenos Aires.

En 1931 lo convocaron a Dominicana como Superintendente de Educación de Vicente L. Trujillo, pero sólo duró dos meses en el cargo, antes de entrar en serios desacuerdos con el dictador, por lo que retornó a sus cátedras a la Argentina.

En ese país, el retiro de las concepciones positivistas, el desarrollo de nuevas corrientes psicológicas, el surgimiento de nuevas formas de conocer vinculadas a la sensibilidad y la conmoción que significaba la Gran Guerra para la racionalidad moderna y las certezas del siglo XIX, produjeron nuevas condiciones de posibilidad para el discurso pedagógico. En las primeras décadas del nuevo siglo, diversas naciones latinoamericanas produjeron un proceso de modernización cultural impulsada desde el Estado, especialmente a través de las leyes educacionales. Sin embargo, no se consolida del mismo modo ese otro proceso moderno que es el de la ampliación de la ciudadanía ya que el Estado era administrado por una minoría con un bajo nivel de participación política. Ese contraste será un terreno propicio para el florecimiento de demandas políticas crecientes, reclamando la inclusión de sectores sociales, ideas políticas y derechos sociales.

\footnotetext{
${ }^{28}$ Moya Lopez, "Pedro Henríquez Ureña", 83.

${ }^{29}$ Ibidem, 84.
} 
Los años de entreguerras estuvieron marcados por la posibilidad de abrir nuevos interrogantes y tensiones que generaba la crisis social; a partir de allí, se irán ensayando nuevas formas de articulación entre sociedad y Estado. En el período de entreguerras, el perímetro del Estado era algo ya establecido, fuera de discusión en sus notas constitutivas. El volumen de lo social y la democratización de sus modos de organización, en cambio, eran aun objeto de pensamiento y de acción político-educativa.

El sistema educativo atendió, con operaciones pedagógicas propias, las tensiones que los procesos de modernización cultural y social introducían en la vida cotidiana, proponiendo patrones de selección y valoración de nuevas subjetividades. En ellos puede encontrarse desde la apertura de otras fuentes de conocimiento e ideales de ciudadanía y moralidad hasta formas privilegiadas de representación del mundo que pugnaban por hacerse presentes en el período. Como parte de la disputa hegemónica, ellas pugnaron para que sus sensibilidades integraran la "cultura de Estado", la "cultura pública", o la "cultura oficial". La influencia de Henry Bergson que Henríquez Ureña traía consigo- inspiraba las críticas al mecanicismo positivista y el racionalismo gnoseológico, proponiendo la intuición como fuente de conocimiento de lo real. La realidad para Bergson era un proceso perenne de creación, sin principio ni fin, que no se presentaba dos veces en la misma forma, un fluir constante, sin división alguna de partes. El intuicionismo influyó fuertemente formas y contenidos gnoseológicos y estéticos. Una pedagogía asentada en la función moral que, sin menoscabar la función del pensamiento y la sabiduría, buscaba asentar su legitimidad en una diferente relación con los alumnos-discípulos-jóvenes. ${ }^{30}$

En la Argentina, Henríquez Ureña se ganó la vida como profesor en escuelas secundarias (entre 1926 y 1946), además de participar en la producción del ambiente literario. En ello llevó adelante su propósito de la enseñanza idealista. Valoraba como los jóvenes argentinos desarrollaban interés por el estudio de los problemas sociales, la preocupación por la justicia y el bien de todos. Distintos autores -como Ernesto Sábato, su alumno- han destacado la práctica de un simil a la mayéutica desarrollado por el rpofesor Ureña:

Su conversación era una mayéutica constante: sacaba el alma afuera a sus interlocutores (...) Lo enfrentaba a uno consigo mismo. En lo íntimo, era más honda, más socrático de Henríquez Ureña. Sin saberlo, enseñaba a ver, a oir, a pensar y sucitaba una verdadera reforma en la cultura. ${ }^{31}$

Interpretó esa participación como un recambio generacional y el fin de la concepción mecanicista de la educación del positivismo (que coaccionaba la personalidad del estudiante), implicando su constitución como sujeto autónomo capaz de ejercer su plena voluntad de vivir y actuar libre. Encerraba también esta última postulación de influencia bergsoniana, además de la emergencia de los estudiantes como un actor que gravitaría en el desenvolvimiento científico-educativo, la del imaginario democrático argentino y la del igualitarismo radicalizado que esparcía la revolución proletaria. Podía recorrerse así el camino hacia la síntesis de Rodó: la eficiencia en lo material y el idealismo en lo espiritual.

\footnotetext{
${ }^{30}$ Patricia Funes, "Pedro Henríquez Ureña", 23.

${ }^{31}$ Alfonso Reyes, "Encuentros con Pedro Henríquez Ureña", Revista Ibero- americana, 41-42 (1956): 54-55.
} 
La cultura hispanoamericana abarcaba para Ureña la lengua española, la historia literaria y las instituciones, pero incluía también la historia de las ideas, la historia social, la pintura y la música. Esa concepción le permitió construir uno de los "grandes relatos" que hacen posible una identidad integradora y largas continuidades. ${ }^{32}$ En su errar por múltiples exilios Henríquez Ureña fue anexando y reapropiándose de distintas tradiciones. Lo estética fue para Henríquez siempre constitutivo: es en la obra de arte que los seres humanos pueden reconocer sus potencialidades.

En los años de las protestas reformistas y apoyado por ese movimiento, Alejandro Korn ocupó posiciones institucionales claves en las universidades de Buenos Aires y de La Plata, en las cuáles impulsó su reorganización disciplinar y científica y la renovación de su claustro docente. Se debía elaborar una filosofía argentina para el mundo de posguerra y esa era una misión ineludible de la universidad. He ahí entonces un proyecto filosófico que encauzaba los objetivos de cambios educativos del reformismo, pero que por la vastedad de su propósito intelectual, los excedía ampliamente. Korn buscó comprometer en el mismo a sus discípulos y colegas, pero como la enseñanza profesional era todavía un ámbito limitado para poder desplegarla, conformó en 1922 al margen de la cátedra, el grupo de estudios Renovación, que se comprometió con su programa intelectual. ${ }^{33}$ Ese clima intelectual interpeló a Henríquez Ureña. Ese mismo año ese colectivo universitario lo impulsó con la creación de la Compañía Teatral del Grupo de Estudiantes Renovación, y un año después con la de la revista Valoraciones. Humanidades. Crítica y Polémica y de la Editorial Renovación. ${ }^{34}$ Fueron esas tres experiencias vinculadas, las que configuraron su acción intelectual en esos años, pautada por la búsqueda de renovación cultural idealista y humanista en la enseñanza académica, pero que intentó además enriquecer sus manifestaciones en la vida cultural urbana, a través de la difusión en ella de las nuevas voces de la filosofía y la literatura, del teatro y la pintura emergentes o clásicas, recuperadas en la primera posguerra. ${ }^{35}$

La crisis universitaria que desató el movimiento estudiantil era en realidad la expresión de una crisis de época: la de la cultura científico-positivista que informaba sus carreras, disciplinas y saberes como a sus viejos planteles docentes. Y en el planteo de Korn exigía su completa renovación o esa crisis institucional se prolongaría indefinidamente. La participación de los estudiantes en el gobierno de las casas de estudios, era para este profesor condición de esa renovación, ya que, influido por la propuesta orteguiana de las generaciones, esa intervención en los asuntos académicos la aseguraría, porque era la juventud con su malestar intelectual, la que permitiría la evolución de las ideas. Influido por José

\footnotetext{
${ }^{32}$ Díaz Quiñones, "Pedro Henríquez Ureña", 178.

${ }^{33}$ Osvaldo Graciano, "Alejandro Korn y las humanidades en la Universidad Nacional de La Plata", Archivos de Ciencias de la Educación 8 (2014).

Recuperado de http://www.archivosdeciencias.fahce.unlp.edu.ar/article/view/Archivos08a04.

${ }^{34}$ Fernando Rodríguez, "Inicial, Sagitario y Valoraciones. Una aproximación a las letras y la política de la nueva generación americana", La cultura de un siglo. América Latina en sus revistas, ed. S. Sosnowski (Buenos Aires: Alianza, 1999), 217-247

${ }^{35}$ Osvaldo Graciano, "Alejandro Korn y las humanidades", 178.
} 
Ortega y Gasset, interpretó esa participación como un recambio generacional y el fin de la concepción mecanicista de la educación del positivismo (que coaccionaba la personalidad del estudiante), implicando su constitución como sujeto autónomo capaz de ejercer su plena voluntad de vivir y actuar libre. Encerraba también esta última postulación de influencia bergsoniana, además de la emergencia de los estudiantes como un actor que gravitaría en el desenvolvimiento científico-educativo, la del imaginario democrático argentino y la del igualitarismo radicalizado que esparcía la revolución proletaria. Y precisamente sus escritos trasuntaban el igualitarismo social que la posguerra imponía, principio político que incluyó como dimensión relevante de su pensar filosófico en esta etapa. ${ }^{36}$

\section{Palabras de cierre}

La guerra europea con sus características de conflagración técnica, total y nihilista causó un impacto sorpresivo e inusitado en los intelectuales latinoamericanos. Su significación histórica y cultural profunda, como el ocaso de una época y la oportunidad del principio de otra. su evaluación de las consecuencias culturales de la guerra fue el punto de partida de un sistemático camino de crítica del pensamiento de la "cultura científica", que consideraba una herencia del siglo XIX ya agotada en su capacidad de dar dirección a la sociedad y a sus instituciones, en particular a las de educación. ${ }^{37}$ La guerra europea, llevaba a su consumación la destrucción material de una época completa, la de la civilización burguesa y no era casual porque esa civilización se había desarrollado sobre el despliegue supremo del dominio de la naturaleza a través de la técnica y de una visión materialistautilitaria del mundo y del hombre, cuyo fin último de la existencia se reducía a ello. La otra consecuencia era que el positivismo, la filosofía que había provisto los valores sociales y culturales a ese despliegue histórico, se encontraba también agotado y esa guerra lo convertía en una filosofía perimida.

El papel jugado por Pedro Henríquez Ureña por el humanismo que postulaba su pensamiento, una dimensión que hacía a su condición de saber de la polis y, por lo tanto, asomaba como el privilegiado para la constitución de una cultura fundada en valores éticos, sociales y estéticos que orientasen la conducta social y política del pueblo en su primera experiencia cultural. El desafío radicó en conciliar en el proceso de incorporación a un conjunto de alteridades complejas y de distinta entidad: étnicas, culturales, religiosas, sociales y regionales. Funes remarca la importancia que el pensamiento antiimperialista de posguerra tuvo en la medida en que constituyó un dilema que configuró un perímetro inclusivo a escala regional y señaló destinos y estrategias comunes para América Latina. La revisión de relaciones entre sociedad y estado, república, democracia, revolución, socialismo, corporativismo, se entrelazan a la definición de las naciones en la búsqueda de principios de legitimidad alternativos. ${ }^{38}$

${ }^{36}$ Oscar Terán, En busca de la ideología argentina (Buenos Aires: Catálogos, 1986), 179-194.

${ }^{37}$ Oscar Terán, Vida intelectual en el Buenos Aires fin de siglo (1880-1910). Derivas de la "cultura científica" (Buenos Aires: Fondo de Cultura Económica, 2000).

${ }^{38}$ Patricia Funes, Op. Cit, 2006, 25. 
El intelectual dominicano Pedro Henríquez Ureña (1884-1946) aportó su perspectiva de problemática latinoamericana y los debates sobre la identidad autónoma y la conflictividad ante la necesidad de expandir las prácticas democráticas en el ámbito escolar. Sus ideas tuvieron especial influencia en la educación secundaria a partir de una pedagogía que tematizaba la paz y la conflictividad social, así como la formación estética y la sensibilidad como condiciones para una educación democratizadora.

Sabemos que había llegado a esas conclusiones durante los años de la guerra y aunque remontaba las evidencias de la declinación del positivismo a principios del nuevo siglo, fue la guerra la que marcó a su entender, el fin de la época positivista. Esa era la tesis que había madurado en sus clases: "La crisis del positivismo está representada fuera de toda duda por la guerra actual”. Así, la utopía de América, se no sólo en tanto proyecto cultural afianzador de la identidad hispanoamericana, sino también un ideal de progreso con base en la transformación cultural futura, que se poduciría a través de la educación.

\section{Bibliografía}

Díaz Quiñones, Arcadio. "Pedro Henríquez Ureña: Modernidad, diáspora y construcción de identidades". En Modernización e identidades sociales, editado por Gilberto Giménez and Ricardo Pozas H., 59-117. México: Universidad Nacional Autónoma de México, 1994.

Funes, Patricia, Salvar la Nación. Intelectuales, cultura y política en los años veinte latinoamericanos. Buenos Aires: Prometeo, 2006.

Guerriero, Leila, Pedro Henríquez Ureña (1884-1946). El extranjero. Agencia literaria virtual Librusa, 2003. (consultado el 15 de noviembre de 2019)

Henríquez Ureña, Pedro. "La cultura de las humanidades". En La utopía de América, prólogo de Rafael Gutiérrez Girardot, compilación y cronología de Ángel Rama and Rafael Gutiérrez Girardot, 56-64. Caracas: Biblioteca Ayacucho, 1978.

Henríquez Ureña, Pedro. Seis ensayos en busca de nuestra expresión (1928). Buenos Aires: Cielo Naranja, 2006.

Moya Lopez, Laura. "Pedro Henríquez Ureña: la Identidad Cultural Hispanoamericana”. La Utopía de América Revista de la UNAM 20 (2000): 69-83.

Pita González, Alexandra and Marco Antonio Vuelvas Solórzano. 'La conformación de una genealogía intelectual. El homenaje a Gabino Barreda (1908)". Historia y Espacio 41 (2013): 17-37.

Quintanilla, Susana. Nosotros, la juventud del Ateneo de México. México: Tusquets, 2009.

Reyes, Alfonso and Pedro Henríquez Ureña. Correspondencia. 1907-1914. México: Fondo de Cultura Económica, 1986.

Reyes, Alfonso. "Encuentros con Pedro Henríquez Ureña". Revista Iberoamericana 41-42 (1956): 54-55. 
Ripa Alberti, Héctor. "Discurso en Asamblea Universitaria, 1921”. http://biblioteca.clacso. edu.ar/clacso/gt/20101109120908/24alberdi.pdf (consultado el 16 de noviembre de 2019)

Rodríguez, Fernando. "Inicial, Sagitario y Valoraciones. Una aproximación a las letras y la política de la nueva generación americana". En La cultura de un siglo. América Latina en sus revistas, editado por Susana Sosnowski, 217-247. Buenos Aires: Alianza, 1999.

Sarlo, Beatriz. Una modernidad periférica: Buenos Aires 1920 y 1930. Buenos Aires: Nueva Visión, 2007.

Terán, Oscar. En busca de la ideología argentina. Buenos Aires: Catálogos, 1986.

Terán, Oscar. Vida intelectual en el Buenos Aires fin de siglo (1880-1910). Derivas de la "cultura científica". Buenos Aires: Fondo de Cultura Económica, 2000.

Valerio-Holguín, Fernando. "Pedro Henríquez Ureña: utopía del silencio". Caribbean Studies 39 (1-2) (2011): 195-221. 